\title{
Remote Sensing of Photosynthetic Parameters
}

\author{
Natascha Oppelt \\ Kiel University \\ Germany
}

\section{Introduction}

Remote sensing cannot measure photosynthesis directly. However, remote sensing can provide information about parameters directly or indirectly connected to the photosynthetic activity of a plant or a vegetation canopy.

Since the launch of the first earth resource satellite in 1972 researchers focused on the relationship between vegetation and its radiometric response. Comparisons of ground measurements and data of the first generations of the Landsat series proved very soon the suitability of the red and near infrared bands of the sensors for vegetation analysis. In the following years, various mathematical combinations of the green, red and near infrared bands, the so called vegetation indices (Bannani et al., 1995) were developed to quantify properties of plant canopies such as biomass, productivity or vigour (Pearson \& Miller, 1972; Kauth \& Thomas, 1976; Misra et al., 1977; Huete, 1988). However, the low spectral resolution of those sensors was inadequate to derive biochemical properties of vegetation. The development of hyperspectral instruments with a high number of narrow bands first enabled the quantification of pigment concentration and indices related to the photosynthetic capacity of vegetation. While field spectrometers were used to derive pigment concentration of single leaves or small plots of vegetation, the advent of airborne imaging spectrometers such as the compact airborne spectral imager casi, the Airborne Visible/Infrared Imaging Spectrometer AVIRIS or the HyMAPTM Hyperspectral Scanner enabled the monitoring of vegetated canopies and small landscape sections from the 1980s. Since then a new generation of indices was developed considering limitations known from the first generation (Baret et al., 1989; Qi et al., 1994). However, due to the restriction to airborne instruments the acquisition of hyperspectral images was a cost-intensive task. Studies dealing with this kind of sensors assessing biochemical or biophysical plant properties were limited to a relatively small group of scientists and stakeholders.

With the advent of space-borne hyperspectral instruments (e.g. the Compact High Resolution Imaging Spectrometer CHRIS (since 2001), the Moderate Resolution Imaging Spectroradiometer MODIS (since 2002) and the Environmental Mapper EnMAP (launch in 2015)) monitoring of biophysical parameters related to photosynthesis becomes increasingly operational. The growing availability as well as the reduced costs for hyperspectral data had a great impact on the numbers of studies and literature dealing with pigment assessment of native and cultivated vegetation canopies on various spatial scales.

Vegetation type and species composition strongly affect the derivation of biochemical plant properties and components. Biochemical components (e.g. chlorophyll content) and related 
biophysical properties (e.g. light use efficiency (LUE)) are more species-specific than biomespecific (Ahl et al., 2004). Thus, biome-related parameter retrieval and canopy-related studies require different ambitions for parameter retrieval. Large scale and global approaches require the development of simple, generalized representations of the most important plant processes and can be used in different biomes with a minimum of modifications (Running \& Hunt, 1993; Running et al., 2004). Contrary local studies focus on single crop canopies with specific approaches to estimate parameters affecting photosynthesis such as crop chlorophyll, nitrogen content or uptake, or stress factors for different species and phenological stages (e.g. Daughtry et al. 1992; Gamon et al., 1992; Gilabert et al., 1996; Rascher \& Pieruschka, 2007; Yoder \& Pettrigrew-Crosby, 1995). Photosynthetic parameter retrieval usually serves for applications related to precision farming, e.g. crop growth modelling, application of fertilizers, herbi- and fungicides and yield forecasting (e.g. Haboudane et al., 2002, 2004; Hank et al., 2007; Malenowski et al., 2009; Oppelt et al., 2007; Strachan et al., 2008).

This study focuses on the assessment of the chlorophyll content of wheat (Triticum aestivum L.) canopies using airborne hyperspectral data. Several types of indices were applied and resulting results are discussed. Then the estimation of crop growth, gross and net primary production using the indices is described exemplarily for two applications: the use of indices for operational remote sensing products as well as the integration of indices with physically based crop growth modelling

\section{Vegetation radiometric properties}

Plant leaves show typical characteristics in their reflectance in the visible (VIS), near-infrared (NIR) and shortwave infrared (SWIR) parts of the electromagnetic spectrum (Figure 1). In general, VIS is dominated by the absorption features of leaf pigments, mainly by the chlorophylls. In the near-infrared region, high reflectance is due to the internal structure of plant mesophyll. The internal structure of leaves with numerous refractive discontinuities and intercellular air spaces scatters incident radiation and results in a large proportion to be passed back as reflected radiation. Plant water absorption features affect the reflectance behaviour in the SWIR leading to a strongly decreased reflectance at high plant water contents.

Light reaction is commonly measured using the chlorophyll absorption features in the VIS, which are known to correspond well with the fraction of absorbed photosynthetically active radiation (fAPAR) (Schurr et al., 2006). At the canopy level, the efficiency of carbon fixation is denoted. LUE refers to the projected ground surface and describes the net canopy $\mathrm{CO}_{2}$ fixation. The spatial variability of $L U E$ results in enormous variations of net photosynthetic productivity (NPP), which ranges from 30 to $1000 \mathrm{~g} \mathrm{C} \mathrm{m}^{-2}$ in different ecosystems (Schurr et al., 2006). Thus knowledge of the spatial distribution of LUE, fAPAR or chlorophyll is essential for a realistic estimation of photosynthetic processes.

To extract pigment information, a range of other factors that influence vegetation reflectance must be taken into account. The leaf reflectance may vary independently of pigment concentrations due to differences in internal structure, surface characteristics and moisture content. Furthermore, the reflectance spectrum of a whole canopy is influenced by factors such as the effects of leaf area, the orientation of leaves, ground coverage, and presence of non-leaf elements, areas of shadow and soil surface reflectance. These factors obscure the 
relationship between spectral reflectance and chlorophyll concentration (Blackburn, 2006) and thus have to be considered.

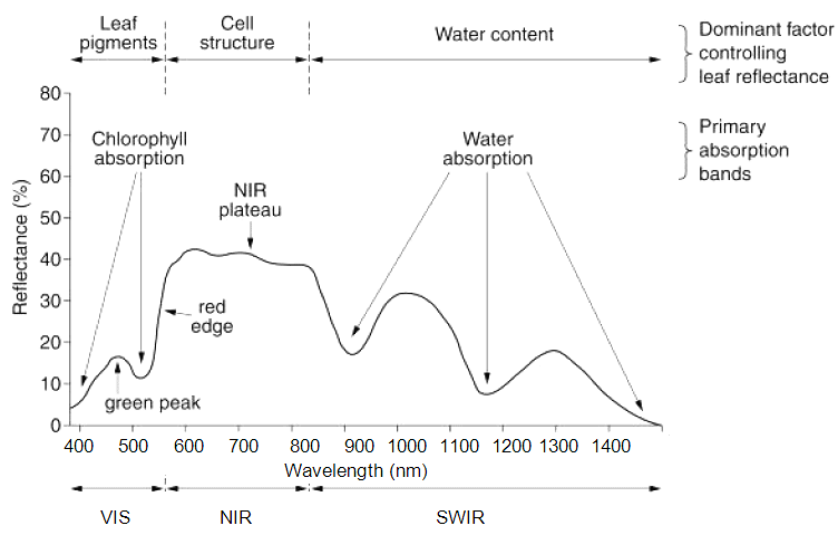

Fig. 1. Typical spectral reflectance characteristics of green leaves (Keyworth et al., 2009, modified)

\section{Material and methods}

To gather field and hyperspectral remote sensing data, intensive field campaigns were conducted during the growing seasons in 2004 and 2005 in a test site located in the Bavarian Alpine foothills. The study area, hyperspectral data assessment and processing, field measurements, data processing and analysis will be described in the following section.

\subsection{Study sites}

The study area is located in the county Gilching, $25 \mathrm{~km}$ south-west of Munich, Germany, (upper left corner $48^{\circ} 8^{\prime} \mathrm{N}, 11^{\circ} 17^{\prime} \mathrm{E}$ ). The study area is characterized by an ever-moist and temperate climate with a mean temperature of $8.3^{\circ} \mathrm{C}$ (1961-1990), ranging from $-5^{\circ} \mathrm{C}$ and 2 ${ }^{\circ} \mathrm{C}$ in January to $12^{\circ} \mathrm{C}$ and $23^{\circ} \mathrm{C}$ in July. The mean annual sum of precipitation is $900 \mathrm{~mm}$ with $540 \mathrm{~mm}$ during the growing season of wheat (April to August). Two climatological stations of the Bavarian network of agro-meteorological stations enable access to local weather monitoring. The stations provide meteorological data such as precipitation, soil and air temperature, total irradiance and humidity (www.lfl.bayern.de/agm /start.php).

For each 2004 and 2005, one field of winter wheat grown with the unawned cultivar Achat was chosen as a test field. The plots were characterized by similar soil conditions (cambisols according to the FAO classifications scheme) and have been managed by the same farmer, who enabled information on management data such as fertilizer and herbicide application as well as the date of sowing, soil treatment and harvest. A detailed description of the test site and the field plots is provided by Oppelt (2010).

During 2004 and 2005, the growing conditions are similar regarding temperature and radiation which are within the standard deviation of the average values, but precipitation varied strongly. The area received $164 \mathrm{~mm}$ more precipitation in 2005 than in 2004 . Frequent and heavy rainfalls during July and August of 2005 were exceptional and caused many crops to mould upon the field. 


\subsection{The Airborne Visible/Infrared Imaging Spectrometer AVIS}

The Airborne Imaging/Infrared imaging Spectrometer AVIS was built at the Department for Geography of the Ludwig-Maximilians-University in Munich (Germany) (Oppelt \& Mauser 2001, 2004, 2006, 2007). The second generation of the sensor, AVIS-2, was operated for this study. AVIS-2 is a CCD-based system operating in the VIS and NIR (400 nm to $900 \mathrm{~nm}$ ) spectral range with a spectral resolution of $9 \mathrm{~nm}$. The system is based on a spectrograph (SPECIM Imspector V9NIR), mounted to a black and white 2/3" CCD-video camera (Vosskühler 1300) and a filter-lens system. Table 1 summarizes the specifications of AVIS-2; the sensor, its specification and calibration are described in detail by Oppelt \& Mauser (2007).

\begin{tabular}{|l|l|}
\hline Nominal spectral range [nm] & $400-900$ \\
\hline Analyzable spectral range [nm] & $420-880$ \\
\hline Spectral resolution [nm] & 9 \\
\hline Radiometric sampling [bits] & 16 \\
\hline Number of bands & 64 \\
\hline Signal to Noise Ratio (SNR) [dB] & 65 \\
\hline Spatial resolution [pixels per line] & 300 \\
\hline Spatial sampling [pixels per line] & 640 \\
\hline Field of view (FOV) [rad] & 1.0 \\
\hline Navigation systems & INS, GPS \\
\hline Period of operation & since 2001 \\
\hline
\end{tabular}

Table 1. AVIS-2 specifications

\subsection{AVIS data}

AVIS was designed to be operated on different platforms, such as Dornier DO-27 or DO-228 and microlight aircrafts, where the sensor is mounted on vibration dampening mounts. For this study AVIS-2 was operated on a Dornier DO-27 aircraft flown by pilots of the Bavarian armed forces.

Four AVIS-2 acquisitions are available for the growing periods in 2004 and 2005. In 2004, the sensor was flown on March 31, May 25 and June 8. One overflight was conducted in 2005, i.e. on July 6. To ensure comparable illumination and viewing geometries, the overflights were conducted in the principal plane with a flight azimuth of about $0^{\circ}$. The data were gathered in a time period between 10 and $14 \mathrm{hrs}$ UTC resulting in sun azimuth angles between $31.5^{\circ}$ and $37^{\circ}$. The ground sampling distance (GSD) for the overflights was $4 \mathrm{~m}$.

The radiometrical pre-processing of the data included correction of sensor dark current, CCD homogeneity and smile effect (Oppelt \& Mauser, 2007). Then the data were corrected atmospherically and reflectance calibrated using an approach based on MODTRAN-4 (Berk et al., 2000). The data for the parameterization of the atmosphere were estimated using climatological data of the Bavarian agro-meteorological network. The geometric processing of the AVIS data was carried out using data of a differential Global Positioning System (dGPS) and an Inertia Navigation System (INS), which were mounted on the sensor. INS and dGPS data were stored in the header of each image line and provide data of the aircraft location (latitude, longitude and altitude) and pointing information (roll, pitch and yaw). Combined with a digital elevation model, these data are used to compensate for the motion of the aircraft and rectify the data to a respective coordinate system. The geometric 
correction was carried out by means of the header information, aerial orthophotography and ground control points applying a second-order polynomial function in ESRI ARCGIS 9.1. Figure 2 presents an image stripe with exemplary reflectance spectra.
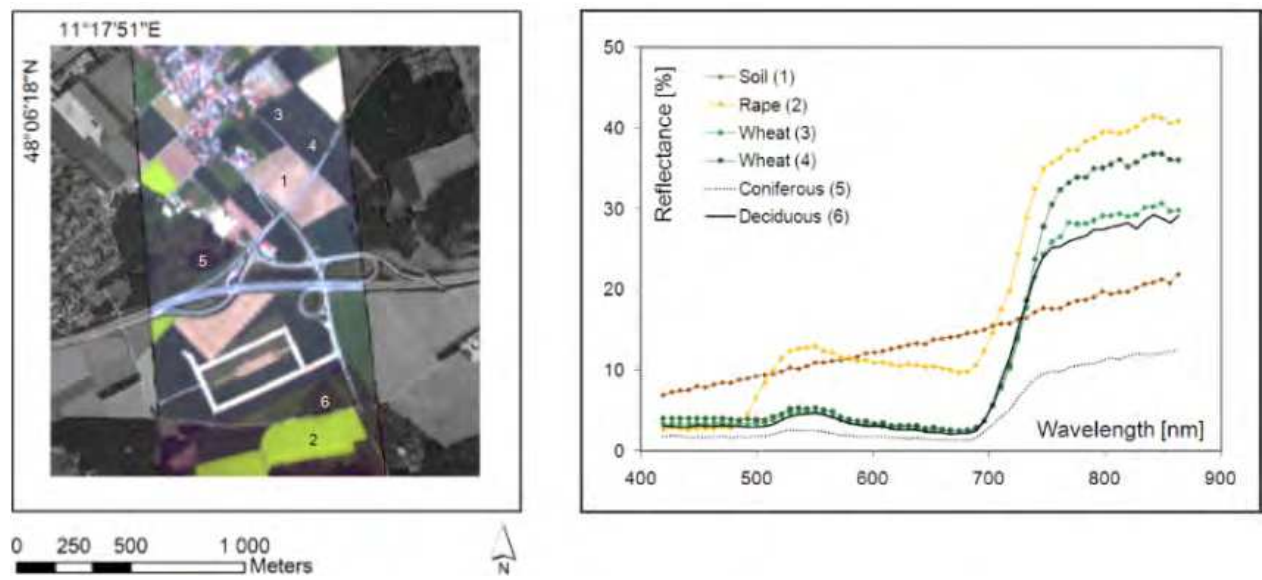

Fig. 2. AVIS real colour image acquired on May 25, 2004 (left hand side); the data were the processed geometrically and radiometrically as well as reflectance calibrated; the numbers in the AVIS image indicate the location of the reflectance spectra presented on the right hand side.

The reflectance spectra of the different wheat pixels unveil the potential of hyperspectral remote sensing for vegetation monitoring. In the VIS, the pixels reflect the solar radiation nearly identical. Thus, for the human eye, which is represented by the real colour composite, these wheat patches look nearly identical. The differences become obvious when looking at the NIR part of the reflectance spectra. The higher reflectance of wheat (4) indicates that the vegetation is more densely developed than the wheat (3) patch.

\subsection{Field measurements}

For every field, five sampling points were selected diagonally in the field and fixed via handheld GPS (GARMIN VISTA). The locations of the sampling points were selected in close cooperation with the farmers in order to gather ground truth data from areas in the field that exhibited differences in plant development and yield over recent years.

At the sampling points weekly measurements were conducted between April and harvest (beginning of August) including phenological stage, plant height and DM (separated into stem, leave and fruit fraction). Measurements of leaf area were conducted using a LI-COR LAI 2000 plant canopy analyzer. Leaf chlorophyll was measured from April to the beginning of ripening. After sampling the leaves were frozen immediately in liquid nitrogen and taken to the laboratory, where the chlorophyll analysis was conducted according to the procedure described by Porra et al. (1989). The resulting chlorophyll concentration per weighted portion was multiplied with the leaf dry matter resulting in the total chlorophyll which is stored in the leaves within a square metre on ground $\left[\mathrm{mg} \mathrm{m}^{-2}\right]$. Field spectrometer measurements (Ocean Optics SD-2000 combined with SD-2000 NIR) were conducted concurrent to the AVIS overpasses to validate AVIS processing results (Oppelt, 2010). 

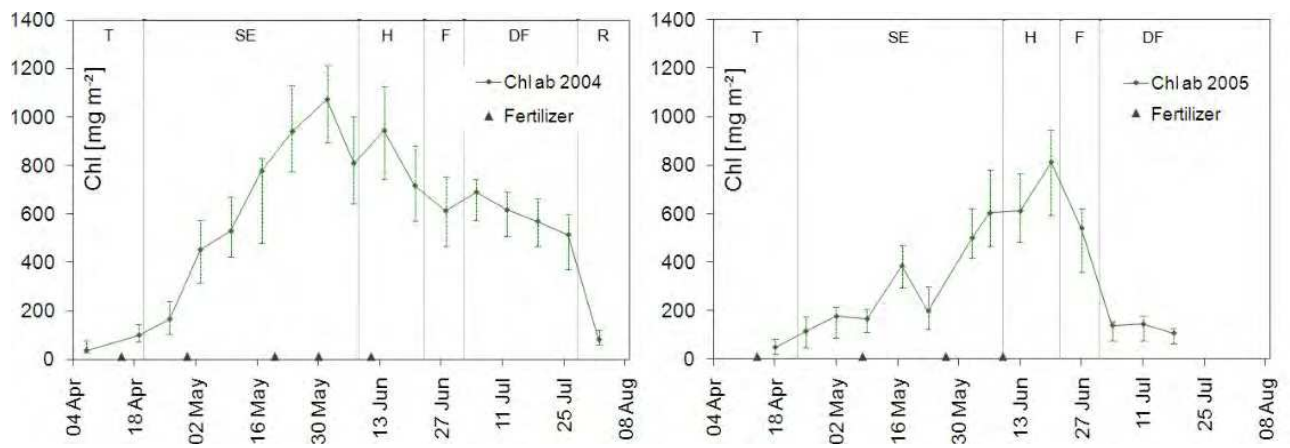

Fig. 3. Results of total chlorophyll measurements during the growing seasons 2004 and 2005; the rhombuses correspond to the mean field values during the phenological stages ( $\mathrm{T}$ = tillering; $\mathrm{SE}=$ stem elongation; $\mathrm{H}=$ heading; $\mathrm{F}=$ flowering; $\mathrm{DF}=$ development of fruit; $\mathrm{R}=$ ripening); the error bars mark the minimum and maximum values measured the sampling points indicating the scattering of the chlorophyll measurements

Figure 3 presents the results of the in situ chlorophyll measurements. Despite the nearly parallel phenological development, the chlorophyll content varies considerably in both amount and chronology. In 2004, canopy leaf chlorophyll develops with a general increase during the vegetative growth to $1100 \mathrm{mg} \mathrm{m}^{-2}$ chlorophyll and a decrease during the generative growing phase. This pattern is obviously superimposed by the development of leaf biomass, which increases during spring and decreases after flowering. Figure 3 also indicates that fertilization affects the general course of canopy chlorophyll; chlorophyll content increases after the application of fertilizer. The error bars indicate the variability of chlorophyll within a vegetation stand. As anticipated, the heterogeneity within the field generally is high during vegetative growth while during ripening the canopy reveals a more homogeneous chlorophyll distribution.

In 2005, the canopy chlorophyll increases with a relatively soft increase until May, where a notable decrease can be observed. Late frost events led to a reduced metabolic activity resulting in decreased chlorophyll contents (Oppelt, 2010). After the frost events the wheat canopy exhibits a strong increase in canopy chlorophyll to $682 \mathrm{mg} \mathrm{m}^{-2}$, which was promoted by high temperatures and a high amount of incoming radiation in June. Due to the wet conditions in July, the plants began to mould, which led to a considerable reduced yield in 2004 (average of $7.01 \mathrm{t} \mathrm{ha}^{-1}$ in comparison to $8.3 \mathrm{t} \mathrm{ha}^{-1}$ in 2005 (Oppelt, 2010)). The decay of the plants is accompanied by a rapid decomposition of chlorophyll during anthesis. These results underline that a general assumption of the canopy chlorophyll can be deceptive for the assessment of vegetation photosynthesis. Variations in crop chronology due to different weather conditions as well as existing spatial heterogeneities may distort an expected universal course of the metabolic activity even at a single crop stand.

\subsection{Indices for the derivation of canopy chlorophyll}

A large variety of approaches has been developed for estimating chlorophyll content. Modelling studies provided good evidence that reflectance is more sensitive to high pigment concentrations at wavelengths where pigment absorption is low. Contrary, spectral regions with high absorption are more sensitive to low pigment concentrations (Blackburn, 2006; 
Jacquemoud \& Baret, 1990). Empirical studies have confirmed this statement and demonstrated that reflectance at wavelengths corresponding to the lower and upper flanks of the major chlorophyll absorption feature in the Red is most sensitive to the normal range pigment concentrations in most leaves (Carter \& Knapp, 2001) and canopies (Filella et al., 1995; Yoder \& Pettrigrew-Crosby, 1995). In young and senescent leaves and canopies bands at the centre of absorption features are most sensitive to low pigment concentrations (Sari et al., 2005).

To deal with the difficulties in relating reflectance to individual bands due to variations in the controlling factors on canopy reflectance, many approaches use reflectance in multiple bands. Most of them have employed ratios of narrow bands in spectral regions that are sensitive to pigments and those areas that are not sensitive. They were proposed as a means of solving the problems of overlapping absorptions of different pigments (Chappelle et al., 1992) and the effects of leaf and canopy structure (Peñuelas et al., 1995). Many indices have been derived for chlorophyll quantification and are based on ratios of bands in the VIS and NIR (Filella et al., 1995; Sims \& Gamon, 2002), in the Red (Vogelman et al., 1993), or in the NIR and red edge region (Gitelson \& Merzlyak, 1997).

As mentioned previously, canopy reflectance results from a complex interaction between pigment concentrations, canopy structure, background signal and illumination conditions (sun-sensor-target geometry). Moreover, vegetation indices that are insensitive to soil optical properties seem to be relatively insensitive to chlorophyll variations. Conversely, most indices sensitive to chlorophyll content variability are strongly affected by the differences in the canopy vegetation cover (Haboudane et al., 2002). Various indices have been developed to be both sensitive to a broad range of chlorophyll content and robust towards different types of noise. Four approaches, which represent different types of indices, are discussed in this paper, i.e. a hyperspectral derivate of the Normalized Vegetation Difference Index, the Optimized Soil Adjusted Vegetation Index, the Photochemical Reflectance Index and the Chlorophyll Absorption Integral.

\subsubsection{Normalized Difference Vegetation Index}

Rouse and colleagues (1974) published the probably best common well-known index, the Normalized Difference Vegetation Index (NDVI) (Equation 1). The NDVI belongs to the first generation of indices which were based on empirical methods designs for a specific sensor, i.e. Landsat MSS.

$$
N D V I=\frac{\left(R_{N I R}-R_{\operatorname{Re} d}\right)}{\left(R_{N I R}+R_{\operatorname{Re} d}\right)}
$$

This index is still used for studying the state of vegetation with various sensors in regional to global applications (Prince \& Tucker, 1996; Hame et al., 1997). However, several studies note that its usefulness depends strongly on noise associated with view angle differences, soil background influences, clouds and cloud shadow, atmospheric influences and topographic effects (Carlson \& Ripley, 1997; Huete et al., 1997; Kim et al., 2010). In addition, saturation of the vegetation index in high biomass conditions or pigment concentrations limits quantitative vegetation assessments (Kim et al., 2010; Oppelt \& Mauser, 2004). Nevertheless, the NDVI is still one of the most common indices. A hyperspectral variant the NDVI was used in this study: 


$$
h N D V I=\frac{\left(R_{827}-R_{668}\right)}{\left(R_{827}+R_{668}\right)}
$$

where $R_{827}$ and $R_{668}$ correspond to the centre wavelength of the respective AVIS bands.

The $h N D V I$ showed high correlations for wheat canopies with medium chlorophyll content, but it becomes insensitive to chlorophyll contents at canopies with low LAI and dense vegetation (Oppelt \& Mauser, 2004).

\subsubsection{Optimized Soil Adjusted Vegetation Index OSAVI}

$O S A V I$ is a derivative of the NDVI and, as indicated by the name, includes a soil adjustment factor. To compensate for the effects of background and soil reflectance, particularly for sparse vegetation cover Rondeaux et al. (1996) introduced the OSAVI:

$$
\text { OSAVI }=\frac{\left(R_{800}-R_{668}\right)}{\left(R_{800}+R_{668}+0.16\right)}
$$

where $\mathrm{R}_{800}$ and $\mathrm{R}_{668}$ correspond to the centre wavelength of the respective AVIS bands.

OSAVI was proposed to reduce the background reflectance contributions and to enhance sensitivity to leaf chlorophyll variability. Its determination requires no knowledge of soil properties resulting in an easy application in the context of operational observations. However, some studies note that OSAVI also becomes insensitive to high chlorophyll contents (Oppelt \& Mauser, 2004; Wu et al., 2008).

\subsubsection{Photochemical Reflectance Index}

The Photochemical Reflectance Index (PRI) was developed by Gamon et al. (1992) to minimize the effects of xanthophylls signal overlapping the chlorophyll spectral features due to sun angle variation. As many other indices the PRI was based on measurements in the laboratory and was then successfully applied and tested on field, air and spaceborne imaging spectrometers (e.g. Gamon \& Qiu, 1999; Penuelas et al., 1997; Sims \& Gamon, 2002; Stylinski et al., 2002; Thenot et al., 2002; Trotter et al., 2002; Weng et al., 2006).

The PRI is calculated as follows (Gamon et al., 1997)

$$
P R I=\frac{\left(R_{531}-R_{570}\right)}{\left(R_{531}+R_{531}\right)}
$$

where $\mathrm{R}$ corresponds to the reflectance at the wavelength considered. The $531 \mathrm{~nm}$ waveband is sensitiv to pigment concentration while the $570 \mathrm{~nm}$ waveband is used as a reference.

The PRI provides an easy measurement of chlorophyll content or LUE (Gamon et al., 1992). Moreover, it can be used for a wide range of species (Gamon et al., 1997). One problematic feature is its high sensitivity to soil reflectance, which has to be taken into account in areas or times with low vegetation cover (Mänd et al., 2010).

\subsubsection{Chlorophyll Absorption Integral}

The Chlorophyll Absorption Integral (CAI) is an approach based on the measurement of the chlorophyll absorption feature depth obtained by fitting a continuum to vegetation reflectance. Kokaly \& Clark (1999) first described this method to assess nitrogen, lignin and cellulose for leaves of different tree and crop species. They used linear segments to 
approximate the continuum. Once the continuum is established, the continuum-removed spectra are calculated by dividing the original reflectance values by the corresponding values of the continuum line. From the continuum-removed reflectance $\mathrm{R}^{\prime}[\%]$, the depth D [\%] in the absorption feature is computed with a uniform interval of $0.1 \mathrm{~nm}$ :

$$
D=1-R^{\prime}
$$

The small interval for calculating the continuum removal was used to overcome difficulties with varying band settings of different sensors which affect $C A I$ values for the same target on the ground (Oppelt, 2008). To minimize the influence of extraneous factors such as atmosphere, soil or topography, the absorption depths are normalized ( $D_{n}$ in Equation 6) (Curran et al., 2001; Kokaly \& Clark, 1999). This is calculated by dividing the absorption depth of each band by the absorption depth at the centre of the absorption $D_{c}$.

$$
D_{n}=\frac{D}{D_{c}}
$$

Kokaly \& Clark (1999) demonstrated that the normalized index exhibits a low sensitivity to background effects due to atmosphere, soil and topography. These results were confirmed at the leaf level by Curran et al. (2001) as well as by Oppelt \& Mauser (2004) for canopy chlorophyll.

The start and end point of the continuum can be chosen according to the band setting of the instrument. The AVIS CAI extends from the Red $(600 \mathrm{~nm})$ to the NIR $(740 \mathrm{~nm})$, whereby the former includes the chlorophyll a absorptions and the latter is an area insensitive to chlorophyll (Gitelsen \& Merzlyak, 1997). Another advantage of CAI is that it includes both the lower and upper flanks of the chlorophyll absorption in the Red as well as the central absorption. Thus it includes wavelengths sensitive to a wide range of chlorophyll contents (Oppelt, 2002, 2010).

\section{Chlorophyll assessment}

The results of the chlorophyll assessment are summarized in Figure 5. As mentioned previously, indices become saturated at high chlorophyll contents. While indices such as the $h N D V I$ and OSAVI saturate at chlorophyll a contents at about $1.0 \mathrm{~g} \mathrm{~m}^{-2}$, the CAI is known to saturate at chlorophyll contents higher than $1.5 \mathrm{~g} \mathrm{~m}^{-2}$ (Oppelt 2002). With increasing chlorophyll content its absorption feature at $680 \mathrm{~nm}$ flattens and narrows. OSAVI and $h N D V I$ are directly affected by reflectance in the Red and tend to saturate by an increase in this spectral region. The high correlations between the CAI and chlorophyll can be ascribed to the fact that the $C A I$ is based on an integrated measurement and therefore is less affected by an increase of reflectance in single wavelengths. The CAI becomes insensitive when the narrowing of the absorption feature leads to a shift of the red edge position towards the Blue (Oppelt, 2002).

The effect of saturation indicates a non-linear relationship, thus an exponential relationship should be expected. However, the chlorophyll contents monitored are below the saturation levels and thus the results can be approximated assuming linear relationships. The regression equations indicate that they do not cross the ordinate at zero, but show an offset, which is caused by the range of chlorophyll contents measured. Hence, the valid range of the chlo- 
rophyll estimation using the equations given in Figure 5 strictly is limited for chlorophyll contents between $200 \mathrm{mg} \mathrm{m}^{-2}$ and $800 \mathrm{mg} \mathrm{m}^{-2}$.
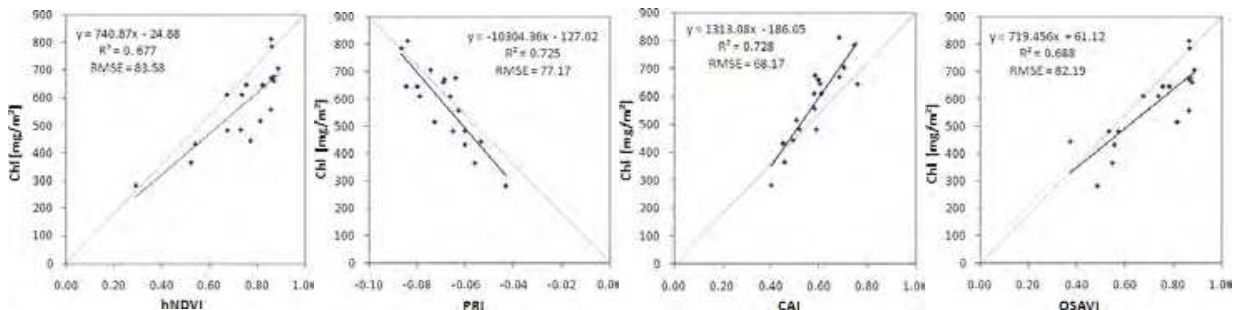

Fig. 5. Linear relationships between vegetation indices and measured canopy chlorophyll; the regression equations are given as well as the coefficient of determination $\left(R^{2}\right)$ and the root mean square error (rmse).
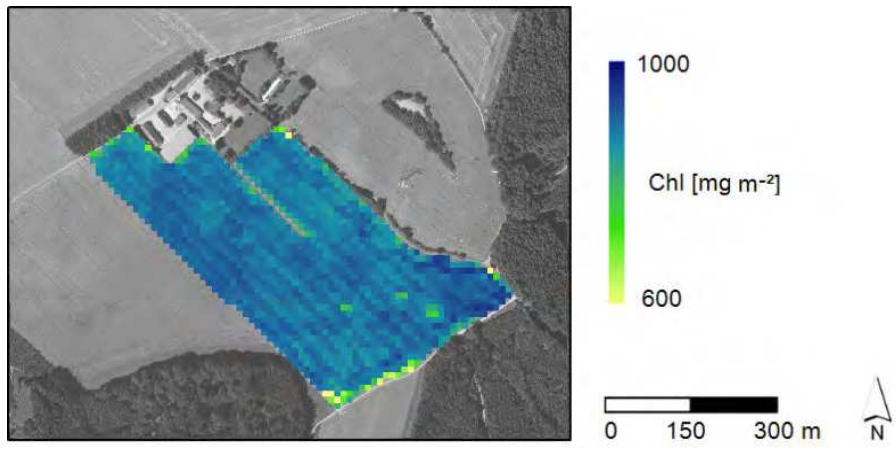

Fig. 6. CAI derived distribution of total canopy chlorophyll as monitored with the AVIS sensor on May 252004

However, the results presented in Figure 5 indicate that $h N D V I$ and OSAVI already saturate at chlorophyll contents above $600 \mathrm{mg} \mathrm{m}^{-2}$, while $P R I$ and CAI are not affected by saturation. PRI shows a significant negative correlation with the canopy chlorophyll while CAI is highly positively correlated. The coefficient of determination $\left(R^{2}\right)$ is relatively high for both $C A I$ and $P R I$ with $C A I$ reveals best results with the lowest root mean square error. Moreover, PRI seems to be not affected by the low leaf area during the AVIS March data. The low saturation level of hNDVI and OSAVI apparently prevents higher coefficients of determination for the crop stands investigated. Figure 6 presents the spatial distribution of canopy chlorophyll content using the regression equation of CAI given in Figure 5 exemplarily for one AVIS acquisition. The Figure shows the existing heterogeneity in the wheat stand at May 25 at the end of stem elongation. The dominant structural pattern is given by the tractor lanes. However, specific areas with similar chlorophyll contents also become visible. Zones of high chlorophyll in the western part as well as in the very east of the field are apparent. The northern and southern field margins are characterized by low chlorophyll contents. A fertilization window is visible in the south-eastern part of the field. This area is not fertilized and therefore is characterized by low chlorophyll contents. 


\section{Estimation of photosynthesis and primary productivity}

Canopy photosynthesis is defined to equal the integrated sum of photosynthesis by leaves in a canopy (Amthor et al., 2001). Jarvis (1993) defined three classes of canopy photosynthesis models; two of them are so-called "big-leave" models which define the canopy as a single layer of vegetation covering the soil. The third model class divides the canopy into multiple layers, which underlie different microclimates and simulate the impact of spatial gradients within the canopy (Baldocchi \& Amthor, 2001).

The terms Gross Primary Production (GPP) and Net Primary Production (NPP) are the most important parameters related to the photosynthetic activity from plant to canopy level. Most crop-growth as well as biome-related models therefore deal with these parameters. GPP is the total amount of carbon fixed by plants through photosynthesis. NPP is the net amount of carbon fixed by plants after the costs of respiration are included (McGuire et al., 1993).

\subsection{Big-leave gross primary productivity}

The simplest big-leaf model assesses canopy GPP based the assumption that photosynthetic assimilation or NPP is proportional to the amount of solar radiation intercepted by vegetation (Monteith, 1972). Thus, canopy photosynthesis can be calculated as a linear function of the photosynthetically active radiation absorbed by the canopy (APAR). The slope of the equation is LUE (Monteith \& Moss, 1977; Ruimy et al., 1995).

$$
G P P=L U E * A P A R
$$

APAR is the product of incoming PAR and the fraction absorbed by the canopy (fAPAR). The measures of $A P A R$ integrate the geographic and seasonal variability of day length and potential incident radiation with daily cloud cover and aerosol attenuation. In addition, APAR implicitly quantifies the amount of leave canopy that is displayed to absorb radiation (Running et al., 2004). This model approach is very simple and enables the estimation of GPP with a very limited number of parameters.

Time and space variability of LUE and APAR can directly be derived using remote sensing and meteorological data (Hilker et al., 2008; McCallum et al., 2009). LUE is influenced by many factors and thus varies in space and time. It is known to vary among crops (Gosse et al.; 1986, Prince, 1991) and nutrient status (Balakrishnan et al. 2001; Oppelt, 2002; Penuelas \& Filella, 1995); however, LUE often is assumed to be constant when growth is not limited by water or nutrient shortage or climate conditions (Ruimy et al., 1995). Some authors propagate the use of PRI as a proxy for LUE (Gamon et al., 1992; Nichol et al. 2000), but Gitelson et al. (2006) stated that PRI is most sensitive to LAI and therefore is difficult to apply on a canopy or even on global scales. Thus, the assessment of LUE differs between authors and application; advantages and disadvantages of the different approaches have to be considered when using vegetation indices as proxies for LUE.

Monteith's logic is fundamental on a suite of operational remote sensing products, e.g. the MODIS GPP, NPP and photosynthesis (PSN) products. Running et al. (2004) described the MODIS algorithms in detail; a simple model based on look-up tables for different biomes is combined with meteorological data. APAR is estimated using the NDVI through Equation 8 (Myneni et al., 1999).

$$
f A P A R=\frac{A P A R}{P A R} \alpha N D V I
$$


This expression is based on results of several studies which found that under specified canopy reflectance properties APAR can be estimated using the NDVI (Asrar et al., 1992; Sellers et al. 1987; Sellers et al., 1992). Myneni et al. (1999) demonstrated that $F A P A R$ is proportional to NDVI if soil background is ideally black and therefore introduced a factor of proportionality which accounts for soil contribution. The linear relationship has been discussed in literature; Ruimy et al. (1995) demonstrated that linearity between APAR and NDVI is only valid during vegetative growth. Moreover, comparison with modelled APAR unveiled that the NDVI-related APAR is significantly lower than independently modelled APAR (Ruimy et al., 1999). A likely explanation is the saturation of the NDVI to high chlorophyll or fAPAR, which also can be observed in Figure 5. Therefore, one of the main problems of GPP assessment using remote sensing data is caused by the uncertainty of a linear NDVI/FAPAR relationship (Gitelson et al., 2006). Besides the controversial discussion, NDVI still is fundamental to MODIS products.

The GPP product is used to calculate net photosynthesis PSN, which is computed as

$$
P S N_{\text {net }}=G P P-R
$$

where $\mathrm{R}$ is an estimate of daily respiration of leaves and roots (Running et al., 2004). MODIS LAI is used to estimate the biomass for the purpose of estimating R (Myneni et al., 1997, 1999). The PSN and GPP products have an 8-day temporal resolution while NPP is an annual value. Figure 6 presents a series of PSN $_{\text {net }}$ products where the test area is located. Each PSN image covers an area of $10^{\circ}$ degrees in latitude and longitude and enables the monitoring of large scale photosynthesis and carbon uptake.

However, with a spatial resolution of $1 \mathrm{~km}$ the MODIS products are suitable rather for large and global scale issues. To gather primary productivity on a smaller scale, crop growth models can be applied.
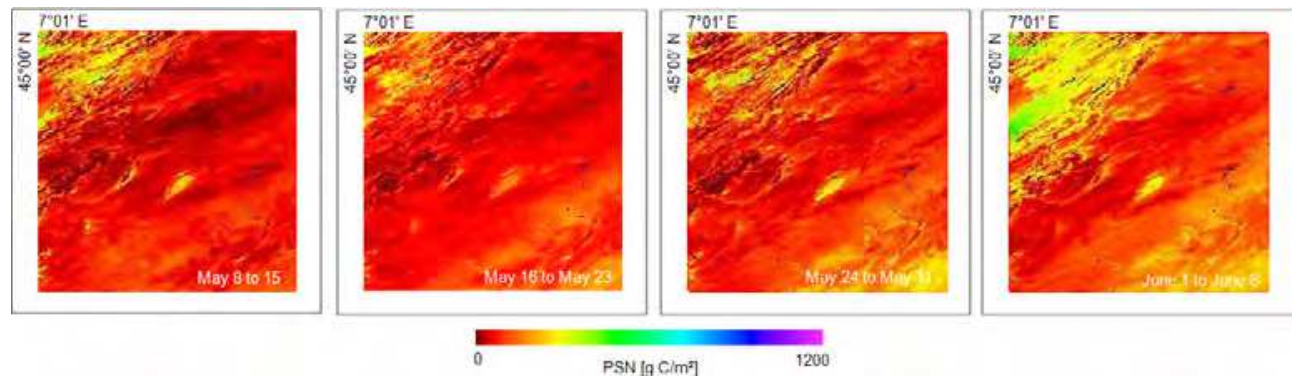

Fig. 6. Series of MODIS 8-day PSN (GSD = $1 \mathrm{~km}$ ) composites from Mai to June 2004 (data source: US Geological Survey, Earth Observation and Science Center)

\subsection{Derivation of NPP using a Vegetation Growth Model Approach}

Multi-layer models are able to consider the impacts of nonlinear physiological and physical processes on canopy photosynthesis (Baldocchi et al., 2001; Wang \& Jarvis, 1990). Yin and Struik (2009) provided an overview of photosynthesis models available for $C_{3}$ and $\mathrm{C}_{4}$ crop modelling. The approach used for this study is the advanced biological sub-model of the process of radiation mass and energy transfer model PROMET (Mauser \& Bach, 2009). 
The core model is based on eight components (meteorology; land surface energy and mass balance; vegetation; snow and ice; soil hydraulics and soil temperature; ground water; channel flow; man-made hydraulic structures (Figure 7) to simulate the water and energy fluxes for variable time steps.

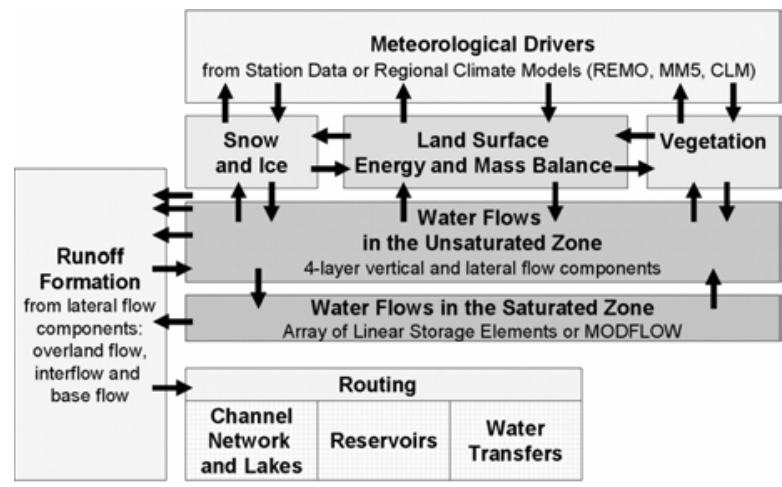

Fig. 7. PROMET core components (Mauser \& Bach, 2009)

\subsubsection{The biological sub-model of PROMET}

The modular structure of PROMET facilitates improvements in particular sub-models. The biological sub-model calculates photosynthesis according to a biochemical approach introduced by Farquhar, von Caemmerer and Berry (1980). NPP is modelled on the basis of the temperature-dependent rate of Ribulose-1.5-Biphosphate (RuBP) reproduction and the availability of Ribulose-1.5-Biphosphate-Carboxylase-Oxigenase (Rubisco), i.e. by simulating the Calvin cycle. The availability and transport of $\mathrm{CO}_{2}$ is regulated by the stomatal resistance of the leaf described by Ball and colleagues (1987). The rate of leaf photosynthesis is modelled in dependence of APAR and the temperature dependent rate of RuBP regeneration. All processes are modelled in two vegetation layers, i.e. a sunlit and a shade layer. PROMET calculates an optimum photosynthesis under given environmental conditions (Hank et al., 2007). The model is able to reproduce effects on plant development that are caused mainly by variations in radiation regime. Effects due to relief, exposition and differences in the soil type or texture can also be modelled well (Hank, 2008; Oppelt, 2010).

The Farquhar and von Caemmerer approach does not require chlorophyll contents but leaf absorptance (abs), which is directly related to CAI (Oppelt, 2010). Abs is dimensionless and refers to the mean relative quantum yield in the range of $P A R$. The quantum yield is the $\mathrm{CO}_{2}$ assimilation in the absence of photorespiration and represents the maximum efficiency with which light can be converted to chemical energy by photosynthesis (Farquhar \& von Caemmerer, 1982). In the model, abs usually is used as a constant value, which now can be dynamised using the CAI-abs remote sensing product. Then, DM is modelled using the constant value $\left(a b s_{\text {const }}=0.83\right.$, Oppelt (2010)) until a remotely sensed $a b s\left(a b s_{R S}\right)$ map is available. Then on, the $a b s_{R S}$ is used to calculate DM.

Lack of remote sensing data or large time gaps between two acquisition dates lead to abs values being inadequate for the specific growing period. These problems can be avoided if the $a b s_{R S}$ values are traced back to $a b s_{\text {const }}$ after a certain period of time. Assuming average growing conditions, the nitrogen in the fertilizer is metabolized within 21 to 30 days 
(Döhler, 2007). Thus the absRs is used for a time period of three weeks before $a b s_{\text {const }}$ is set again, but is replaced again if an additional abs $\operatorname{RS}_{\mathrm{R}}$ map is available for a later day.

To fit the grid size of the other input data of the model (i.e. the limiting resolution of the digital elevation model) the data were resampled to a resolution of $10 \mathrm{~m}$ using a nearest neighbour approach. The resulting root mean square errors (rmse) from the ground control points were less than 0.5 pixels along track and 0.6 pixels across track.

To provide appropriate soil moisture conditions at the beginning of the measurement periods, the simulation run was started about four months prior to the sowing date of the crops (i.e. August 2003 and 2004 respectively).

\subsubsection{Model results and discussion}

NPP is defined as the rate at which vegetation fixes carbon from the atmosphere minus the plant respiration (McGuire et al., 1993); therefore NPP demonstrates its link to DM development during plant growth (Gitelson et al., 2006; Wu et al., 2010). Box et al. (1989) described the relationship between NPP and biomass as follows

$$
N P P=L F+\triangle D M+H
$$

where $L F$ represents the biomass discarded periodically (e.g. litter or dead leaves), $\triangle D M$ is the increment of dry matter and $H$ represents the dry matter lost to herbivores or harvest. For a precision farming managed crop canopy, the loss of biomass due to herbivores and decay of plant material are assumed to be negligible. Therefore, in this study aboveground dry biomass is used as proxy for NPP, but it has to be mentioned that, due to the lack of root biomass measures, it is restricted to above ground biomass and above ground NPP.

Figure 8 presents the average field values of modelled and measured DM in 2004 and 2005. In 2004, PROMET reproduces the field average plant development well, but tends to overestimate DM when used with the constant abs value. The general course of DM is based on a standardized development of canopy leaf area. The LAI measurements conducted during the growing season were used to adapt the standardized canopy leaf area. They are mainly responsible for the excellent results even when PROMET was run without remote sensing data. The modelling of optimum photosynthesis results in increased DM at the early stages of plant growth. The integration of $C A I_{a b s}$ results in a decrease of the modelled average DM at the beginning of tillering (due to March 31 AVIS data) and a slower increase during anthesis and ripening (due to the May 25 and June 8 data). However, only a slight increase in model performance could be observed when looking at the field average.

The results for 2005 clearly demonstrate the limitation of crop modelling. Results shown in Figure 6 demonstrate that PROMET cannot correctly reproduce average DM when factors, which are not driven by radiation regime, influence plant growth and health. PROMET was able to trace the reduced development of leaf area, but could not reproduce the moldering and decay. Unfortunately, the AVIS acquisition in July was far too late to adjust plant development to a more realistic level. The modelled DM is on a lower level compared to 2004, which is due to the influence of the LAI based modelling of the canopy. However, the resulting model performance was poor with high deviations up to $0.46 \mathrm{~kg} \mathrm{~m}^{-2}$ (Figure 9). 


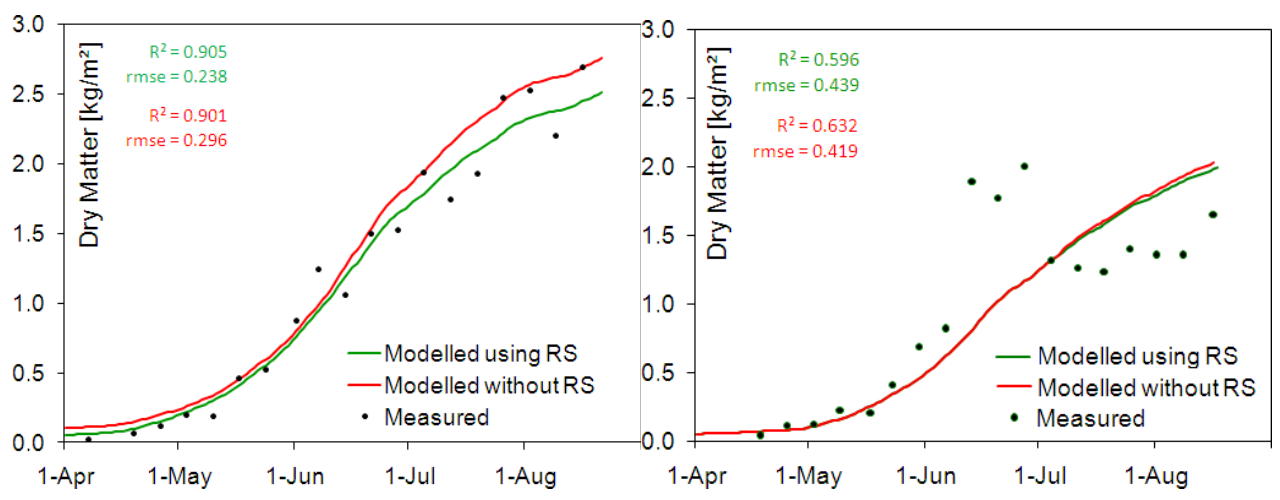

Fig. 8. Comparison of modelled and measured mean field values of DM with or without the integration of remote sensing (RS) data for the growing season in 2004 (left hand side) and 2005 (right hand side)
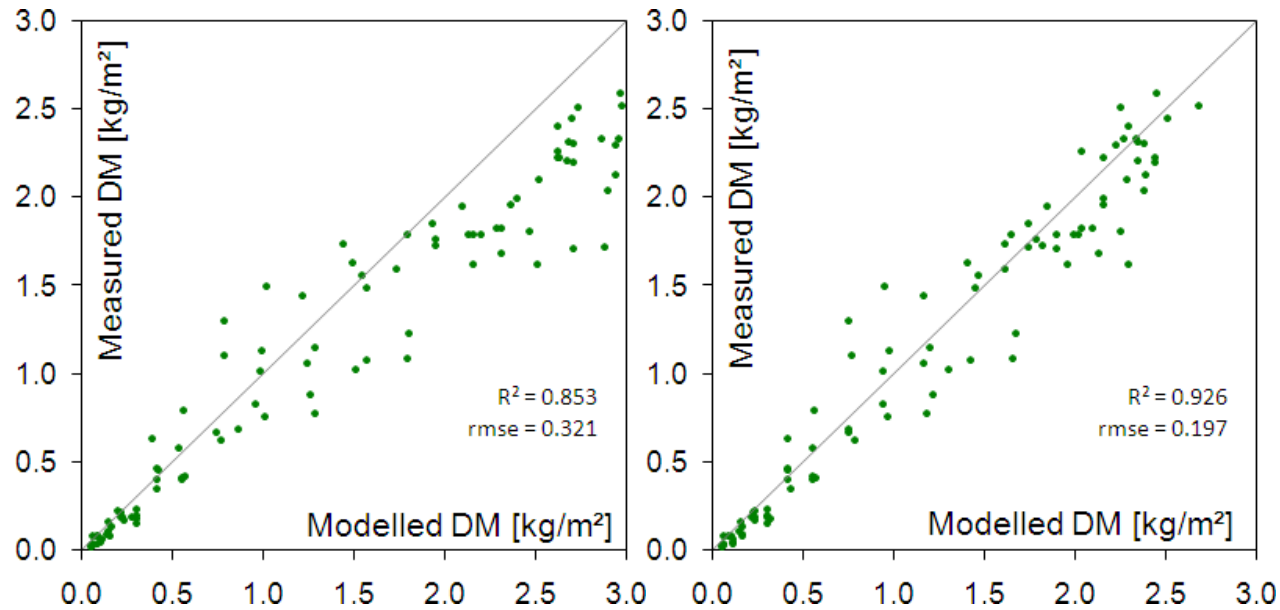

Fig. 9. Results of modelled and measured above-ground DM in 2004 when PROMET is used stand alone (left hand side) and with integration of AVIS data regulating the amount and spatial distribution of chlorophyll (right hand side)

The potential of integrating remote sensing data becomes obvious when looking at the results for the field sampling points (Figure 8). Plant development at the different sampling points can be reproduced more realistically when $a b s_{R S}$ is used instead of $a b s_{\text {const. }}$. The implementation of AVIS data results in a slightly higher coefficient of determination, but rmse was reduced by approximately $30 \%$.

The use of a dynamic abs enables a more realistic modelling of dry matter, i.e. DM production is lowered. However, the results depend strongly - as could have been expected - on the time (or developmental stage of the plants) when remote sensing data are available. The time when a remotely sensed abs distribution can be integrated is crucial for two reasons: firstly, if spatially distributed abs is available at the beginning of the vegetation period, this 
period can be modelled more realistically, because in the early growth stages the abs values turned out to be much lower than the constant value. With progressive plant development the chlorophyll content and therefore the absorptance increase, resulting in a low modelled DM.
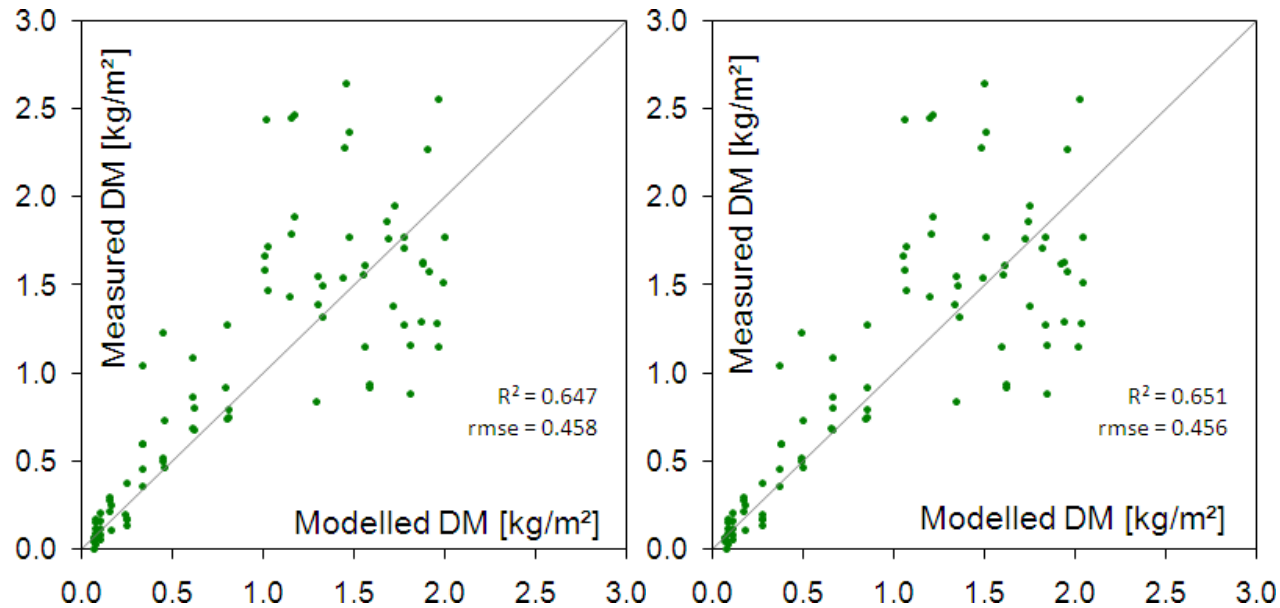

Fig. 9. Results of modelled and measured above-ground DM in 2005 when PROMET is used stand alone (left hand side) and with AVIS data acquired on 5 July (right hand side)

The importance of the phenological stage at which abs $s_{\text {S }}$ is introduced is obvious. The advantage of implementing additional remote sensing data is the adjustment of the canopy absorptance properties, which would generally result in a decrease of DM. Thus model results improve at most when remote sensing data during the early growing stages are available. The AVIS acquisition in 2005 was too late for a proper characterization of the stand, because nearly the whole plant development was modelled with abs const. $_{\text {. }}$

\section{Conclusions}

Remote sensing can provide information about parameters directly or indirectly connected to the photosynthetic activity of a plant or a vegetation canopy. Different types of vegetation indices were applied to estimate total chlorophyll of wheat canopies using airborne hyperspectral data. Validation with field measurements showed that OSAVI and hNDVI tend to saturate at chlorophyll contents above $600 \mathrm{mg} \mathrm{m}^{-2}$ while PRI and CAI were not affected by saturation. PRI showed the highest degree of correlation $\left(\mathrm{R}^{2}=0.725\right)$, but CAI proved the most precise estimation $\left(\mathrm{rmse}=81.1 \mathrm{mg} \mathrm{m}^{-2}\right.$ ).

Vegetation indices can be used as input parameter for calculating photosynthesis from small to global scale. MODIS PSN, GPP and NPP products are based on NDVI measurements and provide information with a spatial resolution of $1 \mathrm{~km}$. Examples of MODIS PSN provide valuable information of photosynthesis at regional to large scales.

To provide NPP on a field scale, the Farquhar - based biological sub-model of PROMET was used as vegetation growth model. PROMET integrates CAI derived leaf absorptance values as input parameter to calculate canopy photosynthesis. To validate model results, canopy 
dry matter was used as a proxy for NPP. Under standard growing conditions, PROMET reproduced average field biomass development well, even without integration of remote sensing data $\left(R^{2}=0.91\right)$. The model calculates optimum photosynthesis under given meteorological conditions and therefore tends to overestimate DM. The integration of remote sensing data adapts varying chlorophyll condition occurring in the field to the model. The results show a general decrease of modelled average DM. However, the heterogeneities in the wheat canopies could be reproduced better when a CAI based absorptance was integrated in PROMET; the resulting degree of correlation increased $\left(R^{2}=0.93\right.$ compared to $R^{2}=$ 0.85 ) while the prediction error decreased by $30 \%$.

The advantage of implementing additional remote sensing data lies in the adjustment of the canopy absorptance properties, e.g. on a deficit in nutrient supply, mechanical inflictions or plant diseases or moulding. Still, the acquisition time is a crucial task for the enhancement of crop growth modelling. If remote sensing data were not available directly after a mechanical inflict or the appearance of diseases, the model is not able to reproduce the changing plant metabolism $\left(\mathrm{R}^{2}=0.65\right)$.

This paper demonstrates that the use of remote sensing data to adapt "real conditions" to models of photosynthesis is very promising, both at field and coarse scale. The success and progress of photosynthetic related MODIS products and the model results emphasize the need for space-borne instruments to enable an operational monitoring with regular acquisitions on a regional and local scale. The advent of the EnMAP instrument in 2015 will hopefully close this gap. In addition, sun induced chlorophyll fluorescence becomes increasingly important in the monitoring of photosynthetic processes. Instruments that measure sun induced fluorescence such as FLEX (candidate for the Earth Explorer mission of the European Space Agency) will contribute significantly to the remote sensing based research in the field of photosynthesis.

\section{Acknowledgments}

The author would like to thank the German Research Foundation (DFG) for funding the project "Coupled analysis of vegetation chlorophyll and water content using hyperspectral, bidirectional remote sensing". Thanks are also due for Mr. Stürzer for continuing access to the test fields and for supporting the study with detailed management data.

\section{References}

Balakrishnan, K., Rajendran, C. \& Kulandaivelu, G. (2001). Differential Responses of Iron, Magnesium, and Zinc Deficiency on Pigment Composition, Nutrient Content, and Photosynthetic Activity in Tropical Fruit Crops. Photosynthetica, 38. 3, pp.477-479.

Baldocchi, D.D. \& Amthor, J. (2001). Canopy Photosynthesis: History, Measurements, and Models. In J. Roy, B. Saugier, \& H. Mooney (Eds.), Terrestrial Global Productivity: Academic Press. San Diego, California, USA.

Ball, J., Woodrow, I. \& Berry, J. (1987). A model predicting stomatal conductance and its contribution to the control of photosynthesis under different environmental conditions. Progress in Photosynthesis Research, 4, pp.221-224.

Bannari, A., Morin, D., Bonn, F. \& Huete, A.R. (1995). A review of vegetation indices. Remote Sensing Reviews, 13/1, pp.95-120. 
Baret, F., Guyot, G. \& Major, D. (1989). TSAVI - A vegetation index which minimizes soil brightness effects on LAI and APAR estimation. In Proceedings of IGARSS '89, Vancouver (Canada), pp. 1355-1358.

Barton, C.V.M. \& North, P.R.J. (2001). Remote sensing of canopy light use efficiency using the photochemical reflectance index: Model and sensitivity analysis. Remote Sensing of Environment, 78. 3, pp.264-273.

Berk, A., Anderson, G., Acharya, P., Bernstein, L., Chetwynd, J., Hoke, M., Matthew, M., Shettle, E. \& Adler-Golden, S. (2000). MODTRAN 4 Version 2 User Manual. Air Force Research Laboratory, Space Vehicle Directorate.

Blackburn, G. (1998). Quantifying chlorophylls and carotenoids at leaf and canopy scales: an evaluation of some hyperspectral approaches. Remote Sensing of Environment, 66, pp.273-285.

Blackburn, G. (2006). Hyperspectral remote sensing of plant pigments. Journal of Experimental Botany, 10.1093, pp.1-13.

Box, E., Holben, B. \& Kalb, V. (1989). Accuracy of the AVHRR vegetation index as a predictor of biomass, primary productivity and net $\mathrm{CO}_{2}$ flux. Vegetation, 80, pp.71-89.

Carlson, T.N. \& Ripley, D.A. (1997). On the relation between NDVI, fractional vegetation cover, and leaf area index. Remote Sensing of Environment, 62. 3, pp.241-252.

Carter, G. \& Knapp, A. (2001). Leaf optical properties in higher plants: linking spectral characteristics to stress and chlorophyll concentrations. American Journal of Botany, 88 , pp.677-684.

Chen, J.M., Liu, J., Cihlar, J. \& Goulden, M.L. (1999). Daily canopy photosynthesis model through temporal and spatial scaling for remote sensing applications. Ecological Modelling, 124/2-3, pp.99-119.

Curran, P., Dungan, J. \& Peterson, D. (2001). Estimating the foliar biochemical chemistry of leave reflectance spectrometry: Testing the Kokaly and Clark methodology. Remote Sensing of Environment, 76, pp.349-359.

Daughtry, C.S.T., Gallo, K.P., Goward, S.N., Prince, S.D. \& Kustas, W.P. (1992). Spectral estimates of absorbed radiation and phytomass production in corn and soybean canopies. Remote Sensing of Environment, 39, pp.141-152.

Davidson, M., Berger, M., Moya, I., Moreno, J., Laurila, T., Stoll, M. \& Miller, J. (2003). Mapping Photosynthesis from Space. a new vegetation-fluorescence technique. ESA bulletin, pp.34-37.

DeRose, R.J., Long, J.N. \& Ramsey, R.D. (2011). Combining dendrochronological data and the disturbance index to assess Engelmann spruce mortality caused by a spruce beetle outbreak in southern Utah, USA. Remote Sensing of Environment, 115. 9, pp.2342-2349.

Döhler, H. (2007). Energiepflanzen (Energy Plants). Darmstadt: KTBL Verlag.

Farquhar, G.D. (2001). Models of Photosynthesis. Plant Physiology, 125, pp.42-45.

Farquhar, G.D., Caemmerer, S. von \& Berry, J. (1980). A biochemical model of photosynthetic $\mathrm{CO}_{2}$ assimilation in leaves of $\mathrm{C} 3$ species. Planta, 149, pp.78-90.

Féret, J.B. \& Asner, G.P. (2011). Spectroscopic classification of tropical forest species using radiative transfer modeling. Remote Sensing of Environment, 115. 9, pp.2415-2422. 
Filella, I., Serrano, L., Serra, J. \& Penuelas, J. (1995). Evaluating wheat nitrogen status with canopy reflectance indices and discriminant analysis. Crop Science, 35, pp.14001405.

Galvão, L.S., dos Santos, J.R., Roberts, D.A., Breunig, F.M., Toomey, M. \& Moura, Y.M. (2011). On intra-annual EVI variability in the dry season of tropical forest: A case study with MODIS and hyperspectral data. Remote Sensing of Environment, 115. 9, pp.2350-2359.

Gamon, J., Serrano, L. \& Surfus, J. (1997). The Photochemical Reflectance Index: An Optical Indicator of Photosynthetic Radiation Use Efficiency across Species, Functional Types, and Nutrient Levels. Oecologia, 112, pp.492-501.

Gamon, J.A., Peñuelas J. \&. Field C. B. (1992). A narrow-wave band spectral index that track diurnal changes in photosynthetic efficiency. Remote Sensing of Environment, 41, pp.35-44.

Gamon, J.A. \& SURFUS, J.S. (1999). Assessing leaf pigment content and activity with a reflectometer. New Phytologist, 143, pp.105-117.

Gilabert, M.A., Soledad, G. \& Melia, J. (1996). Analyses of spectral-biophysical relationships for a corn canopy. Remote Sensing of Environment, 55. 1, pp.11-20.

Giles, A.B., Massom, R.A., Heil, P. \& Hyland, G. (2011). Semi-automated feature-tracking of East Antarctic sea ice from Envisat ASAR imagery. Remote Sensing of Environment, 115. 9, pp.2267-2276.

Gitelson, A.A. \& Merzlyak, M.N. (1997). Remote estimation of chlorophyll content in higher plant leaves. International Journal of Remote Sensing, 18, pp.2691-2697.

Glenn, E., Huete, A., Nagler, P. \& Nelson, S. (2008). Relationship Between Remotely-sensed Vegetation Indices, Canopy Attributes and Plant Physiological Processes. Sensors, pp.2136-2160.

Goerner, A., Reichstein, M., Tomelleri, E., Hanan, N., Rambal, S., Papale, D., Dragoni, D. \& Schmullius, C. (2011). Remote sensing of ecosystem light use efficiency with MODIS-based PRI. Biogeosciences, 8, pp.189-202.

Haboudane, D., Miller, J., Tremblay, N., Zarco-Tejada, P. \& Dextraze, L. (2002). Integrated narrow-band vegetation indices for prediction of crop chlorophyll content for application to precision agriculture. Remote Sensing of Environment, 81, pp.416-426.

Haboudane, D., Miller, J.R., Pattey, E., Zarco-Tejada, P.J. \& Strachan, I.B. (2004). Hyperspectral vegetation indices and novel algorithms for predicting green LAI of crop canopies: Modeling and validation in the context of precision agriculture. Remote Sensing of Environment, 90, pp.337-352.

Hank, T. (2008). A Biophysically based Coupled Model Approach for the Assessment of Canopy Processes under Climate Change Conditions. PhD thesis. Department of Geography. Munich.

Hank, T., Oppelt, N. \& Mauser, W. (2007).Physically based modelling of photosynthetic processes. In. Stafford (Ed.). Precision Ariculture 07. Wageningen Acad. Publishers.

Hernández-Clemente, R., Navarro-Cerrillo, R.M., Suárez, L., Morales, F. \& Zarco-Tejada, P.J. (2011). Assessing structural effects on PRI for stress detection in conifer forests. Remote Sensing of Environment, 115, pp.2360-2375. 
Hilker, T., Coops, N., Black, T., Wulder, M.A. \& Guy, R.D. (2008). The use of remote sensing in light use efficiency based models of gross primary production: A review of current status and future requirements. Science of The Total Environment, 404, pp.411-423.

Hilker, T., Coops, N.C., Wulder, M.A., Black, T.A. \& Guy, R.D. (2008). The use of remote sensing in light use efficiency based models of gross primary production: A review of current status and future requirements. Biochemistry of Forested Ecosystems. Science of The Total Environment, 404. 2-3, pp.411-423.

Holben, B.N., Kaufman, Y.J. \& Kendall, J.D. (1990). NOAA-11 AVHRR visible and near-IR inflight calibration. International Journal of Remote Sensing, 11, pp.1511-1519.

Huete, A.R. (1988). A soil-adjusted vegetation index (SAVI). Remote Sensing of Environment, 25, pp.295-309.

Huete, A.R., Liu, H.Q., Batchily, K. \& van Leeuwen, W. (1997). A comparison of vegetation indices over a global set of TM images for EOS-MODIS. Remote Sensing of Environment, 59, pp.440-451.

Jaquemoud, S. \& Baret, F. (1990). PROSPECT: a model of leaf optical properties spectra. Remote Sensing of Environment, 34, pp.75-91.

Jin, Y., Randerson, J.T. \& Goulden, M.L. (2011). Continental-scale net radiation and evapotranspiration estimated using MODIS satellite observations. Remote Sensing of Environment, 115. 9, pp.2302-2319.

Johnson, I.R. \& Thornley, J.H. (1984). A model of instantaneous and daily canopy photosynthesis. Journal of Theoretical Biology, 107. 4, pp.531-545.

Keyworth, S., Jarmann, M. \& Medcalf, K. (2009). Assessing the Extent and Severity of Erosion on the Upland Organic Soils of Scotland using Earth Observation. Environment Systems Limited. Aberystwyth.

Kim, Y., Huete, A.R., Miura, T., \& Jiang, Z. (2010). Spectral compatibility of vegetation indices across sensors: band decomposition analysis with Hyperion data. Journal of Applied Remote Sensing, 4, pp.43520-43531.

Kim, S.-H. (2003). A Coupled Model of Photosynthesis, Stomatal Conductance and Transpiration for a Rose Leaf (Rosa hybrida L.). Annals of Botany, 91, pp.771-781.

M. Begon and A.H. Fitter (Ed.) (1995). Advances in Ecological Research. ISBN 0065-2504: Academic Press.

Malenovsky, Z., Mishra, K.B., Zemek, F., Rascher, U. \& Nedbal, L. (2009). Scientific and technical challenges in remote sensing of plant canopy reflectance and fluorescence. Journal of Experimental Botany, 60, pp.2987-3004.

Mänd, P., Hallik, L., Peñuelas, J., Nilson, T., Duce, P., Emmett, B.A., Beier, C., Estiarte, M., Garadnai, J. \& Kull, O. (2010). Responses of the reflectance indices PRI and NDVI to experimental warming and drought in European shrublands along a north-south climatic gradient. Remote Sensing of Environment, 114. 3, pp.626-636.

Mauser, W. \& Bach, H. (2009). PROMET - Large scale distributed hydrological modelling to study the impact of climate change on the water flows of mountain watersheds. Journal of Hydrology, 376, pp.362-377. 
McCallum, I., Wagner, W., Schmullius, C., Shvidenko, A., Obersteiner, M., Fritz, S. \& Nilsson, S. (2010). Comparison of four global FAPAR datasets over Northern Eurasia for the year 2000. Remote Sensing of Environment, 114, pp.941-949.

McGuire, A.D., Joyce, L.A., Kicklighter, D.W., Melillo, J.M., Esser, G. \& Vorosmarty, C.J. (1993). Productivity response of climax temperate forests to elevated temperature and carbon dioxide: a north american comparison between two global models. Climatic Change, 24, pp.287-310.

Melillo, J.M., McGuire, A.D., Kicklighter, D.W., Moore, B., Vorosmarty, C. \& Schloss, A. (1993). Global climate change and terrestrial net primary production. Nature, 363. 6426, pp.234-240.

Meroni, M., Rossini, M., Guanter, L., Alonso, L., Rascher, U., Colombo, R. \& Moreno, J. (2009). Remote sensing of solar-induced chlorophyll fluorescence: Review of methods and applications. Remote Sensing of Environment, 113, pp.2037-2051.

Monteith, J. (1972). Solar Radiation and Productivity in Tropical Ecosystems. Journal of Applied Ecology, pp.747-766.

Montheith, J. \& Moss, C. (1977). Climate and the Efficiency of Crop Production in Britain. Phil. Trans. R. Soc. Lond. B, 281, pp.277-294.

Myneni, R., Knyazikhin, Y., Zhang, Y., Tian, Y., Wang, Y., Lotsch, A., Privette, J., Morisette, J., Running, R., Nemani, R. \& Glassy, J. (1999). MODIS Leaf Area Index and Fraction of Photosynthetically Active Radiation Absorbed by Vegetation Product. Algorithm Theoretical Basis Document. http:/ / eospso.gsfc.nasa.gov/atbd/modistables.html.

Myneni, R., Ramakrishna, R., Nemani, R. \& Running, S. (1997). Estimation of global leaf area index and absorbed par using radiative transfer models. IEEE Transactions on Geoscience and Remote Sensing, 35, pp.1380-1393.

Newton, P.C.D., Clark, H., Bell, C.C., Glasgow, E.M., Ross, D.J., Yeates, G.W. \& Saggar, S. (1995). Plant Growth and Soil Processes in Temperate Grassland Communities at Elevated $\mathrm{CO}_{2}$. Journal of Biogeography, 22. 2/3, pp.235-240.

Nichol, C.J., Lloyd, J., Shibistova, O., Arneth, A., Roser, C., Knohl, A., Matsubara, S. \& Grace, J. (2002). Remote sensing of photosynthetic-light-use efficiency of a Siberian boreal forest. Tellus B, 54, pp.677-687.

Oppelt, N. (2002).Monitoring of Plant Chlorophyll and Nitrogen Status Using the Airborne Imaging Spectrometer AVIS. Dissertation. Department of Geography, University of Munich.

Oppelt, N., Hank, T. \& Mauser, W. (2007). GVIS - ground based hyperspectral remote sensing. In Proc of the 2nd International Symposium on Optics, Informatics and CyberTechnology (OIC 2007). 8-11 July 2007, Orlando/Florida (USA). CD-Rom publication.

Oppelt, N. \& Mauser, W. (2001). The Chlorophyll Content of Maize (Zea Mays) derived with the Airborne Imaging Spectrometer AVIS. In ISPRS 8th International Symposium "Physical Measurements and Signatures in Remote Sensing", 8-12 January 2001; Aussoir, France), pp.407-412.

Oppelt, N. \& Mauser, W. (2006). Three Generations of the Airborne Imaging Spectrometer AVIS. Expectations - Applications - Results. In Proceedings of SPIE Europhotonics 
Europe. Strasbourg (France), 02.04.-07.04.2006, Vol. 6189, SPIE, Bellingham, Wash. ISBN 97-80819462459

Oppelt, N. \& Mauser, W. (2004). Hyperspectral monitoring of physiological parameters of wheat during a vegetation period using AVIS data. International Journal of Remote Sensing, 25, pp.145-159.

Oppelt, N. \& Mauser, W. (2007). The Airborne Visible/Infrared imaging Spectrometer AVIS: design, characterization and calibration. Sensors, 7, pp.1934-1953.

Pearson, R. \& Miller, L. (1972). Remote Mapping of Standing Crop Biomass for Estimation of the Productivity of the Shortgrass Prairie. In Willow Run Laboratories (Ed.), Proceedings of the Eighth International Symposium on Remote Sensing of Environment: Willow Run Laboratories. Ann Arbor. pp. 1355

Peng, C. \& Apps, M. (1999). Modelling the response of net primary productivity (NPP) of boreal forest ecosystems to changes in climate and fire disturbance regimes. Ecological Modelling, 122. 3, pp.175-193.

Penuelas, J. \& Filella, I. (1998). Visible and near-infrared reflectance techniques for diagnosing plant physiological status. Trends in Plant Science, 3. 4, pp.151-156.

Penuelas, J., Filella, I. \& Gamon, J. (1995). Assessment of Photosynthetic Radiation-Use Efficiency with Spectral Reflectance. New Phytologist, 131, pp.291-296.

Penuelas, J., Llusia, J., Pinol, J. \& Filella, I. (1997). Photochemical reflectance index and leaf photosynthetic radiation-use-efficiency assessment in Mediterranean trees. International Journal of Remote Sensing, 18. 13, pp.2863-2868.

Porra, E.J., Kriedman, P.E. \& Thomson, W. (1989). Determination of accurate extinction coefficients and simultaneous Eq.s for assaying chlorophyll $\mathrm{a}$ and $\mathrm{b}$ extracted with four different solvents. Biochemical and Biophysical Acta, 975, pp.384-394.

Pugnaire, F.I. \& Valladares, F. (2007). Functional plant ecology. (2nd ed.). Boca Raton, FL. 084937488X: CRC Press.

Qi, J., Chehbouni, A., Huete, A.R., Kerr, Y.H. \& Sorooshian, S. (1994). A modified soil adjusted vegetation index. Remote Sensing of Environment, 48. 2, pp.119-126.

Qiu, H.-L., Sanchez-Azofeifa, A. \& Gamon, J. Ecological Applications of Remote Sensing at Multiple Scales. In. Valladares, F. \& Pugnaire, I. (Eds). Functional Plant Ecology, 2nd edition. pp. 655-678.

Rahman, A.F., GAMON, J.A., Fuentes, D.A. \& Roberts, D.A. (2001). Modeling spatially distributed ecosystemflux of boreal forest using hyperspectral indices from AVIRIS imagery. Journal of Geophysical Research, pp.33579-33591.

Rascher, U., Nichol, C.J., Small, C. \& Hendricks, L. (2007). Monitoring Spatio-temporal Dynamics of Photosynthesis with a Portable Hyperspectral Imaging System. Photogram-metric Engineering \& Remote Sensing, 73, pp.45-65.

Rascher, U., \& Pieruschka, R. (2008). Spatio-temporal variations of photosynthesis: the potential of optical remote sensing to better understand and scale light use efficiency and stresses of plant ecosystems. Precision Agriculture, 9, pp.355-366.

Román, M.O., Gatebe, C.K., Schaaf, C.B. \& King, M.D. (2011). Variability in surface BRDF at different spatial scales over a mixed agricultural landscape as retrieved from airborne and satellite spectral measurements. Remote Sensing of Environment, 115. 9, pp.2184-2203. 
Rondeaux, G., Steven, M. \& Baret, F. (1996). Optimization of soil-adjusted vegetation indices. Remote Sensing of Environment, 55. 2, pp.95-107.

Rouse, J., Haas, R., Schell, J., Deering, D. \& Harlan, J. (1974). Monitoring the vernal advancements and retrogradation of natural vegetation. NASA/Gsfc final report.

Ruimy, A., Jarvis, P.G., Baldocchi, D.D. \& Saugier, B. (1995). $\mathrm{CO}_{2}$ Fluxes over Plant Canopies and Solar Radiation: A Review. In M. Begon \& A.H. Fitter (Eds.). Advances in Ecological Research, 26. Pp.1-68.

Running, S.W., Nemani, R., Glassy, J. \& Thornton, P. (1999). MODIS Daily Photosynthesis (PSN) and Annual Net Primary Production (NPP) Product. Algorithm Theoretical Basis Document. http://modis.gsfc.nasa.gov/data/atbd/land_atbd.php.

Running, S.W., Nemani, R., Heinsch, F.A., Zhao, M., Reeves, M.A. \& Hashimoto, H. (2004). A Continuous Satellite-Derived Measure of Global Terrestrial Primary Production. BioScience, 54, p.547-560.

Sari, M., Somnez, N. \& Kurklu, A. (2005). Determination of seasonal variations in solar energy utilization by the leaves of Washington navel orange trees (Citrus sinensis L. Osbeck). International Journal of Remote Sensing, 26, pp.3295-3307.

Schurr, U., Walter A. \& Rascher, U. (2006). Functional dynamics of plant growth and photosynthesis - from steady-state to dynamics - from homogeneity to heterogeneity. Plant, Cell and Environment, 29, pp.340-352.

Steven, M.D., Malthus, T.J., Baret, F., Xu, H. \& Chopping, M.J. (2003). Intercalibration of vegetation indices from different sensor systems. Remote Sensing of Environment, 88. 4, pp.412-422.

Strachan, I., Pattey, E., Salustro, C. \& Miller, J. (2008). Use of hyperspectral remote sensing to estimate the gross photosynthesis of agricultural fields. Canadian Journal of Remote Sensing. Canadian Journal of Remote Sensing, 34. 3, pp.333-341.

Suárez, L., Zarco-Tejada, P.J., González-Dugo, V., Berni, J.A.J., Sagardoy, R., Morales, F. \& Fereres, E. (2010). Detecting water stress effects on fruit quality in orchards with time-series PRI airborne imagery. Remote Sensing of Environment, 114. 2, pp.286-298.

Thenot, F., Methy, M. \& Winkel, T. (2002).The Photochemical Reflectance Index (PRI) as water-stress index. International Journal of Remote Sensing, 23, pp.5135-5139.

Tilstone, G.H., Angel-Benavides, I.M., Groom, S. \& Sathyendranath, S. (2011). An assessment of chlorophyll-a algorithms available for SeaWiFS in coastal and open areas of the Bay of Bengal and Arabian Sea. Remote Sensing of Environment, 115. 9, pp.22772291.

Trotter, G.M., Whitehead, D. \& Pinkney, E.J. (2002).The photochemical reflectance index as a measure of photosynthetic light use efficiency for plants with varying foliar nitrogen contents. International Journal of Remote Sensing, 23. 6, pp.1207-1212.

Weng, J., Liao, T.H.M., Chung, C., Lin, C. \& Chu, C. (2006). Seasonal variation in photosystem II efficiency and photochemical reflectance index of evergreen trees and perennial grasses growing at low and high elevations in subtropical Taiwan. Tree Physiology, 26, pp.1097-1104.

Wu, C.; Niu, Z.; Tang, Q. \& Huan, W. (2008). Estimating chlorophyll content from hyperspectral vegetation indices: Modeling and validation. Remote Sensing of Environment, 148, pp. 1230-1241. 
Yin, X. \& Struik, P.C. (2009). C3 and C4 photosynthesis models: An overview from the perspective of crop modelling. Recent Advances in Crop Growth Modelling. NJAS Wageningen Journal of Life Sciences, 57. 1, pp.27-38.

Yoder, B., \& Pettrigrew-Crosby, R. (1995). Predicting nitrogen and chlorophyll content and concentrations from reflectance spectra $(400-2500 \mathrm{~nm})$ at leaf and canopy scales. Remote Sensing of Environment, 53, pp.191-211.

Zhao, M., Heinsch, F., Nemani, R. \& Running, S.W. (2005). Improvements of the MODIS terrestrial gross and net primary production global data set. Remote Sensing of Environment, 95. 2, pp.164-176. 


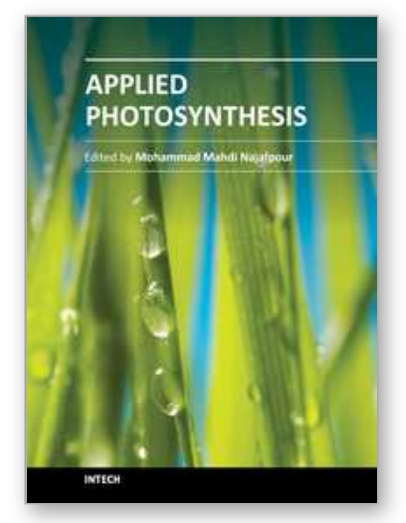

\author{
Applied Photosynthesis \\ Edited by Dr Mohammad Najafpour
}

ISBN 978-953-51-0061-4

Hard cover, 422 pages

Publisher InTech

Published online 02, March, 2012

Published in print edition March, 2012

Photosynthesis is one of the most important reactions on Earth, and it is a scientific field that is intrinsically interdisciplinary, with many research groups examining it. This book is aimed at providing applied aspects of photosynthesis. Different research groups have collected their valuable results from the study of this interesting process. In this book, there are two sections: Fundamental and Applied aspects. All sections have been written by experts in their fields. The book chapters present different and new subjects, from photosynthetic inhibitors, to interaction between flowering initiation and photosynthesis.

\title{
How to reference
}

In order to correctly reference this scholarly work, feel free to copy and paste the following:

Natascha Oppelt (2012). Remote Sensing of Photosynthetic Parameters, Applied Photosynthesis, Dr Mohammad Najafpour (Ed.), ISBN: 978-953-51-0061-4, InTech, Available from:

http://www.intechopen.com/books/applied-photosynthesis/remote-sensing-of-photosynthetic-parameters

\section{INTECH}

open science | open minds

\author{
InTech Europe \\ University Campus STeP Ri \\ Slavka Krautzeka 83/A \\ 51000 Rijeka, Croatia \\ Phone: +385 (51) 770447 \\ Fax: +385 (51) 686166 \\ www.intechopen.com
}

\author{
InTech China \\ Unit 405, Office Block, Hotel Equatorial Shanghai \\ No.65, Yan An Road (West), Shanghai, 200040, China \\ 中国上海市延安西路65号上海国际贵都大饭店办公楼 405 单元 \\ Phone: +86-21-62489820 \\ Fax: $+86-21-62489821$
}


(C) 2012 The Author(s). Licensee IntechOpen. This is an open access article distributed under the terms of the Creative Commons Attribution 3.0 License, which permits unrestricted use, distribution, and reproduction in any medium, provided the original work is properly cited. 